\title{
Parasite control practices in Polish horse farms
}

\author{
MAŁGORZATA RAŚ-NORYŃSKA, RAJMUND SOKÓt
}

\begin{abstract}
Department of Parasitology and Invasive Diseases, Faculty of Veterinary Medicine, University of Warmia and Mazury, ul. Oczapowskiego 13, 10-718 Olsztyn, Poland
\end{abstract}

\section{Raś-Noryńska M., Sokół R. \\ Parasite control practices in Polish horse farms}

Summary

Virtually all horses in Poland periodically receive deworming treatment. In view of the emerging anthelmintic resistance it is important to know the current parasite control practices used by Polish horse owners. In order to assess the situation and analyze it in terms of the risk of drug resistance, a questionnaire survey was forwarded to 300 horse establishments. The response rate was $49.6 \%$. The average number of deworming treatments in adult horses was determined at 2.1. and 2.8 for youngstock per calendar year. The most commonly used drugs were ivermectin, pyrantel pamoate and moxidectin. Almost $73 \%$ of respondents indicated that they take into consideration the resistance of parasites. However, only $4.03 \%$ of the responders regularly send faecal samples from all horses for parasitological examination. In ca. $92 \%$ of cases the person administrating the drug guessed the weight of the horse by visual evaluation. Generally, little attention was paid to pasture hygiene and prevention of parasitic infection. The responses indicate a high level of awareness among horse owners of the need to control parasites. They also show the large involvement of veterinarians as a source of advice about deworming practices, so we concluded that the most appropriate way to achieve improvement would be implementation of further education programmes for veterinarians.

Keywords: parasite control, horses, resistance

Gastrointestinal parasitic infections periodically affect the majority of grazing horses. The number of horses in Poland is estimated at 300,000 (http://cbdk. pl/liczba-koniowatych-2013). Most horses receiving veterinary care are periodically dewormed and the veterinarians are the only source of anthelmintics. In Poland, endoparasite control strategies generally involve regular, routine administration of anthelmintics before and after the pasture period, which in the country's climatic conditions usually lasts from May to September. This practice is justified in the life cycle of most nematodes, and it maintains parasite populations at a relatively low level. The prophylactic use of anthelmintics without a parasitological diagnosis before treatment is garnering increasing controversy due to growing levels of drug resistance $(5,14,32,36)$. The factors that contribute to anthelmintic resistance include high frequency of treatments, overuse of drugs belonging to the same chemical group, underdosing, absence of weight monitoring, and "prophylactic" mass treatments $(12,13,20,26,27,31,32,35)$. Benzimidazole (BZ) resistance in cyathostomin populations is now highly prevalent and reported worldwide $(2,8,16,22,23)$. In Poland, benzimidazole resistance in cyathostomins was confirmed by Balicka-Ramisz and Ramisz (1), and Gawor and Kita (10). Resistance to tetrahydropyrimidines (THP) and pyrantel (PYR) was reported in the USA and Europe $(4,17,25,33)$. The reports documenting the reduced efficiency of ivermectin (IVM) against horse nematodes have been published in both Europe and in the USA $(3,6,11,30$, $32,33)$. In last years there were also reports suggesting reduced efficacy of moxidectin in the USA and the UK $(20,21,34)$.

Studies performed in various countries have demonstrated that for a long time parasite control strategies in horses had promoted an increase in frequency of drug administration, up to the introduction of daily doses of pyrantel administered in the feed mix (available only in the US). The aim of the study is to analyse existing parasite control practices of Polish horse owners in view of growing anthelmintic resistance. A questionnaire survey was carried out among horse owners to assess the situation and evaluate the existing risk of drug resistance. To the best of our knowledge, no other studies on equine intestinal worm control strategies in Poland have been performed to date.

\section{Material and methods}

The study was performed in 2015/2016. A questionnaire relating to parasite control was developed and forwarded to 300 horse establishments from different provinces 
(voivodeships) in Poland. The questions are listed in Tab. 1. The results are presented descriptively and in graphs. The percentage response to several questions was calculated.

A total of 149 subjects participated in the survey (49.6\%). The questionnaire was filled by 88 owners of 1692 warmblood horses and 61 owners of 483 cold-blood horses coming from 10 out of 16 voivodeships. The number of animals ranged from 1 to more than 500 . Ninety-one percent of warm-blooded horses were kept for breeding and recreation purpose and 9\% were sport horses. Young stock

Tab. 1. Questionnaire survey about deworming practices in horses sent to horse owners

1. Type and usage of animals

\begin{tabular}{|c|c|c|c|}
\hline \multicolumn{2}{|c|}{ warm blooded horses } & \multicolumn{2}{|c|}{ b) cold blooded horses } \\
\hline - breeding & $\square$ & - breeding & $\square$ \\
\hline - sport & $\square$ & - labour & 口 \\
\hline - recreatio & $\square$ & - meat & $\square$ \\
\hline
\end{tabular}

2. Number of horses in the herd

3. Herd structure: stallions $\square \quad$ mares $\square \quad$ youngstock $\square \quad$ geldings $\square$

4. Person responsible for the deworming owner $\square \quad$ zootechnician $\square \quad$ veterinarian $\square$

5. Frequency of deworming

$\begin{array}{lll}1 \times / \text { year } \square & 2 \times / \text { year } \square & 3 \times / \text { year } \square \\ 4 \times / \text { year } \square & 5 \times / \text { year } \square & >6 \times / \text { year } \square\end{array}$

6. Season of deworming: spring $\square \quad$ summer $\square \quad$ autumn $\square \quad$ winter $\square$

7. Reason for this schema: veterinary advice $\square \quad$ manufacturer's leaflet $\square$ zootechnitian advice $\square \quad$ tradition $\square$

8. Are all horses treated at the same time: yes $\square \quad$ no $\square$

9. Are parasitological examination performed? all animals $\square \quad$ selected animals $\square \quad$ are not $\square$

10. Did your veterinarian give you advice concerning parasite control or recommend fecal examination? yes $\square \quad$ no $\square$

11. Have you observed parasitic - related ailments: none $\square \quad$ diarrhoea $\square \quad$ colic $\square \quad$ emaciation $\square$ deterioration of the hair coat $\square$

12. Does anthelmintic resistance is taken into consideration when choosing control program?

yes $\square \quad$ no $\square$

13. Which grazed area falls on one horse?

14. Do other species graze on the same pasture? yes $\square \quad$ no $\square \quad$ what species

15. How do you usually cultivate the pastures?

16. Do you carry out faecal removal from the pasture? yes $\square \quad$ no $\square$

17. What criteria determine the choice of the drug? price $\square \quad$ easy application $\square \quad$ veterinary advice $\square$ faecal test $\square \quad$ previous experiences $\square$

18. What drugs are usually used?

19. How often do you rotate the drugs? never $\square \quad$ every treatment $\square$ annually $\square \quad$ every 2-3 years $\square$

20. How do you calculate the dose? visual evaluation $\square \quad$ measurement/weighting $\square$ was kept by $40 \%$ of warm-blooded horse farms. In coldblooded horse farms, $82 \%$ of the animals were kept for breeding purposes, $15 \%$ were bred for slaughter and only $3 \%$ were used for labour. Young horses (up to 2 years of age) were kept by $80 \%$ of the surveyed farms.

\section{Results and discussion}

The majority of respondents $(59.7 \%)$ indicated that the owner was responsible for deworming, whereas in $13.4 \%$ of cases, deworming was the responsibility of the zootechnician or the owner in cooperation with the veterinarian $(13.4 \%)$. In $14.1 \%$ of cases, the relevant decisions were made by the veterinarian providing routine care for horses in the stable.

The number of anthelmintic treatments per year varied from 1 to $>6$, with an average of 2.18 for adult horses and 2.8 for young stock. In farms, where horses were dewormed twice a year, treatment was performed in the spring and autumn. Horses were treated more than 6 times per year in only one establishment (Fig. 1). Eighty-six percent of the responders claimed that deworming treatment was provided simultaneously to all horses. Young horses were generally treated separately.

According to $60.1 \%$ of the respondents, a given deworming strategy was chosen based on the information and advice from their veterinarian, $25.5 \%$ based their choice on customary practice, $9.4 \%$ - on information from the zootechnician, and $6 \%-$ on leaflets provided by the manufacturers of anthelmintic drugs.

The most commonly used drugs were ivermectin in different formulations (including injectable ivermectin for cattle), pyrantel pamoate and moxidectin. The respondents based their choice of drug on the veterinarian's suggestion $(59.1 \%)$, price $(51 \%)$, previous experience $(28.8 \%)$, and ease of application (16.1\%) and the results of parasitological examinations (9.4\%).

When inquired about drug rotation, $32.9 \%$ of respondents claimed to change the applied drugs every $2-3$ years, $30.9 \%$ - every year, $16.1 \%$ - every treatment, whereas $20.1 \%$ relied on the same drug. Nearly $73 \%$ of respondents indicated that parasite resistance

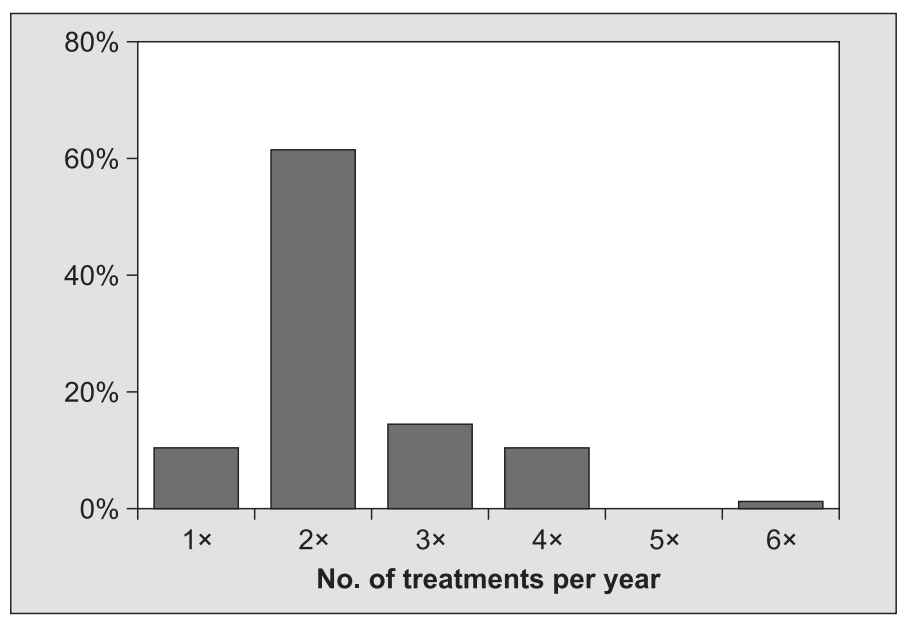

Fig. 1. Responses to question about the number of treatments per year 
was an important factor influencing their choice of a deworming method. However, only $4.03 \%(n=6)$ of the responders regularly submitted faecal samples for parasitological examination. In $21.5 \%$ of the surveyed farms, faecal samples from selected horses were sent for analyses, but not on a regular basis. Fifty-five percent of the respondents admitted that they had received advice concerning parasite control from their veterinarian or were advised to submit faecal samples for parasitological examination. In only $8.1 \%(n=12)$ of the evaluated establishments, the dose of the anthelmintic drug was determined by measuring horses with a grid tape or by weighing, whereas in $91.9 \%$ of cases, the person administering the drug guessed the horse's weight based on a visual evaluation.

Fifty-seven percent of the respondents had never observed any clinical symptoms that could be indicative of a parasitic infection and the need for deworming. Emaciation was observed in $16.1 \%$ farms, deterioration of the hair coat - in $14.8 \%$, colic - in $7.4 \%$ and diarrhoea - in $5.4 \%$ of the evaluated establishments.

All horses from the surveyed establishments had access to a pasture. The average pasture area per horse was 0.9 ha, varying from 0.1 to $4 \mathrm{ha}$. According to $10.1 \%$ of the respondents, pastures were used for rotation or mixed grazing with cattle. The following 7.4\% of the responders admitted that pastures were occasionally used by wild animals such as roe deer, red deer or moose. Pasture clipping and chain harrowing were indicated by $50.3 \%$ and $36.2 \%$ of the responders as the most prevalent pasture care practices, respectively. In $19.5 \%$ of farms, pastures were regularly fertilised, in $6 \%$ - grass was annually re-sown, whereas in $16.8 \%$ of farms, pastures were not cultivated in any way.

Despite the fact that the reliability of the answers could not be verified, the survey was a valuable source of information about intestinal worm control practices in Poland. The responses indicate that horse owners are highly aware of parasite control requirements. They also indicate high involvement of veterinarians as sources of advice about deworming practices, which could be expected given that anthelmintics in Poland are available on prescription only. More than the half of the respondents received information about parasite control or were advised to submit faecal samples for parasitological analysis. The timing of treatment for cold-blooded horses reared for meat was usually determined by the veterinarian or in close consultation with a veterinarian. The relevant decisions were generally based on legal regulations concerning the administration of veterinary drugs to animals whose meat is intended for human consumption. In this case, the owners were more likely to keep full veterinary documentation and observe the required waiting periods. The owners of 1 to 3 horses were more likely to delegate the responsibility for parasite control to a veterinarian.
The vast majority of the respondents provided simultaneous treatment for all horses, and the most commonly used drugs were ivermectin and pyrantel, which is consistent with the results obtained in Italy $(26,29)$, Sweden $(23,25)$ Germany $(9,15,29)$ and the UK $(19,29)$ and Ireland (24). In comparison with Ireland, the UK and Italy where most horses were dewormed at intervals of several weeks, horse owners in Poland provided less frequent treatment for their animals. The average number of deworming treatments in adult horses was determined at 2.1 in Poland, 2.72 in Germany (9), 3.2 in Sweden (25) and 3.7 in Denmark (18). More than half of the respondents had never observed any clinical symptoms that could be associated with internal parasites, and they regarded the existing frequency of deworming treatments and the used formulations as sufficient to counteract the risk. Treatments administered at intervals longer than the pre-patent period may lower the counts of resistant Cyathostomins by diluting them in a potentially susceptible population.

Underdosing is one of the main causes of anthelmintic resistance. Only about $8 \%$ of the surveyed farms weighed each horse in the herd, which increased the risk of weight underestimation. Similar results were obtained by Fritzen et al. (9) and Hinney et al. (15) in Germany, where $94.4 \%$ and $86 \%$ of horse establishments, respectively, determined the weight of the animal by visual assessment. Forty percent of horses were measured and weighted in Ireland (24), and 33\% in Sweden (25).

Seventy-five percent of the respondents declared that their parasite control strategies accounted for anthelmintic resistance. Despite the above, they paid little attention to the prevention of parasitic infections during the pasture period. Similar results were noted in Denmark, where only $10 \%$ of establishments practiced mixed grazing, whereas mixed grazing was much more popular in Italy $(25.3 \%)$ and Germany (17\%). Most respondents declared quartered grazing and quarter rotation if permitted by pasture acreage. Pasture maintenance involved mainly clipping and harrowing. Faeces were removed, although irregularly, in only $14 \%$ of the establishments, which points to low levels of awareness about the risk associated with larval burden in pastures. Faeces were removed in $31 \%$ of Irish pastures and $49 \%$ of British pastures. In $10 \%$ of German stud farms surveyed by Fritzen et al. (9) careful pruning of pastures was the only parasite control measure which eliminated routine drug use.

Anthelmintics should be used rationally and more attention should be paid to the prevention practices, such as frequent parasitological examinations of faecal samples before treatment and the promotion of pasture hygiene, to preserve their effectiveness. In temperate climates, adherence to adequate hygiene standards decreases the number of infective larvae in pastures, 
lowers the risk of infection and minimizes the use of anthelmintics $(2,7,12-14,31)$. Suitable farm management practices combined with the rational use of drugs preceded by parasitological examinations of faecal samples reduce the selection pressure for anthelmintic resistance. Most horse-owners regard their veterinary practitioners as a major source of information about parasites and the only source of anthelmintics; therefore the implementation of further educational programmes for veterinarians seems the most appropriate method to achieve improvement in parasite control.

\section{References}

1.Balicka-Ramisz A. K., Ramisz A. Z.: Benzimidazol resistance in nematode parasites in domesticated animals in north-west part Poland. EJPAU 1999, 2, 2 http://www.ejpau.media.pl/volume2/issue2/animal/art-02.html

2. Bjorn H., Sommer C., Schougard H., Henriksen S. A., Nansen P.: Resistance to benzimidazole anthelmintics in small strongyles (Cyathostominae) of horses in Denmark. Act. Vet. Scand. 1991, 32, 253-260.

3. Boersema J. H., Eysker M., Nas J. W. M.: Apparent resistance of Parascaris equorum to macrocyclic lactones. Vet. Rec. 2002, 150, 279-281.

4. Chapman M. R., French D. D., Monahan C. M., Klei T. R.: Identification and characterization of a pyrantel pamoate resistant cysthostome population. Vet. Parasitol. 1996, 66, 205-212.

5. Dobson R. L., Lejambre L., Gill I. H.: Management of anthelmintic resistance: inheritance of resistance and selection with persistent drugs. Inter. J. Parasitol. 1996, 26, 993-1000.

6. Dudeney A., Campbell C., Coles G.: Macrocyclic lactone resistance in cyathostomins. Vet. Rec. 2008, 163, 163-164.

7. Eysker M., Jansen J., Mirck M. H.: Control of strongylosis in horses by alternate grazing of horses and sheep and some other aspects of the epidemiology of Strongylidae infections. Vet. Parasitol. 1986, 19, 103-115.

8. Fisher M. A., Jacobs D. E., Grimshaw W. T., Gibbons L. M.: Prevalence of benzimidazole-resistance in equine cyathostome populations in south east England. Vet. Rec. 1992, 130, 315-318.

9. Fritzen B., Rohn K., Schneider T., Von Samson-Himmelstjerna G.: Endoparasite control management on horse farms-lessons from worm prevalence and questionnaire data. Equine. Vet. J. 2010, 42, 79-83.

10. Gawor J., Kita J.: Uwagi praktyczne na temat odrobaczania koni. Życie Wet. 2006, 81, 753-756.

11. Hearn F. P., Pertegrine A. S.: Identification of foals incected with Parascaris equorum apparently resistant to ivermectin. J. Am. Vet. Med. Assoc. 2003 $15,482-485$

12. Herd R. P.: Control strategies for ruminant and equine parasites to counter resistance, encystment, and ecotoxicity in the USA. Vet. Parsitol. 1993, 48, 327-336

13. Herd R. P.: Equine parasite control - problems associated with intensive anthelmintic therapy. Equine Vet. Educ. 1990, 2, 41-47.

14. Herd R. P., Coles G. C.: Slowing the spread of anthelmintic resistant nematodes of horses in the United Kingdom. Vet. Rec. 1995, 136, 481-485.

15. Hinney B., Wirtherl N. C., Kyule M., Miethe N., Zessin K. H., Clausen P. H. A questionnaire survey on helminth control on horse farms in Brandenburg, Germany and the assessment of risks caused by different kinds of management. Parasitol. Res. 2011, 109, 1625-1635.

16. Kaplan R. M.: Anthelmintic resistance in nematodes of horses. Vet. Res. 2002, 33, 491-507.

17. Lassen B., Peltola S. M.: Anthelmintic resistance of intestinal nematodes to ivermectin and pyrantel in Estonian horses. J. Helminthol. 2015, 89, 760-763.

18. Lendal S., Larsen M. M., Bjørn H., Craven J., Chriél M., Olsen S. N.: A questionnaire survey on nematode control practices on horses farms in Denmark and the existence of risk factors for the development of anthelmintic resistance. Vet. Parasitol. 1998, 78, 49-63.

19. Lloyd S., Smith J., Connan R. M., Hatcher M. A., Hedges T. R., Humphrey $D$. J., Jones A. C.: Parasite control methods used by horse owners: factors predisposing to the development of anthelmintic resistance in nematodes. Vet. Rec. 2000, 146, 487-492.

20. Lyons E. T., Tolliver S. C., Collins S. S.: Reduced activity of moxidectin and ivermectin on small strongyles in young horses on a farm $(B C)$ in Central Kentucky in two field tests with notes on variable counts of eggs per gram of feces (EPGs). Parasitol. Res. 2010, 107, 1495-1498.

21. Lyons E. T., Tolliver S. C., Collins S. S., Ionita M., Kuzmina T. A., Rossano M. Field tests demonstrating reduced activity of ivermectin and moxidectin against small strongyles in horses on 14 farms in Central Kentucky in 2007-2009. Parasitol. Res. 2011, 108, 355-360.

22. Meier A., Hertzberg H.: Equine strongyles. II. Occurrence of anthelmintic resistance in Switzerland. Schweiz. Arch. Tierheilkd. 2005, 147, 389-396.

23. Nillson O., Lindholm A., Christensson D.: A field evaluation of anthelmintics in horses in Sweden. Vet. Parasitol. 1989, 32, 163-171.

24. O'meara B., Mulcahy G.: A survey of helminth control practices in equine establishments in Ireland. Vet. Parasitol. 2002, 109, 101-110.

25. Osterman Lind E., Rautalinko E., Uggla A., Waller P. J., Morrison D. A., Höglund J.: Parasite control practices on Swedish horse farms. Act. Vet. Scand. 2007, 49, 25-33.

26. Papini R. A., Bernart F. M., Sgorbini M.: A Questionnaire Survey on Intestinal Worm Control Practices in Horses in Italy. J. Equine Vet. Sci. 2015, 35, 70-75. 27. Prichard R.: Anthelmintic resistance. Vet. Parasitol. 1994, 54, 259-266.

28. Samson-Himmelstjerna G. von, Fritzen B., Demeler J., Schurmann S., Rohn K. Schnieder T., Epe C.: Cases of reduced cyathostomin egg-reappearance period and failure of Parascaris equorum egg count reduction following ivermectin treatment as well as survey on pyrantel efficacy on German horse farms. Vet. Parasitol. 2007, 144, 74-80.

29. Samson-Himmelstjerna G. von, Traversa D., Demeler J., Rohn K., Milillo P., Schurmann S., Lia R., Perrucci S., Frangipane Di Regalbono A., Beraldo P., Barnes H., Cobb R., Boeckh A.: Effects of worm control practices examined by a combined faecal egg count and questionnaire survey on horse farm in Germany, Italy and the UK. Parasit. Vectors 2009, 2 (Suppl 2); S3 doi: 10.1186/1756-3305-2-S2-S3

30. Schougaard H., Nielsen M. K.: Apparent ivermectin resistance of Parascaris equorum in foals in Denmark. Vet. Rec. 2007, 160, 439-440.

31. Shalaby H. A.: Anthelmintics Resistance; How to Overcome it? Iran J. Parasitol 2013, 8, 18-32.

32. Traversa D.: Anthelmintic resistance in horse cyathostomins in Europe: curren status and future perspectives. Sci. Parasitol. 2010, 11, 1-6.

33. Traversa D., von Samson Himmelstjerna G., Demeler J. H., Milillo P., Schürmann S., Barnes H., Otranto D., Perrucci S., Frangipane Di Regalbono A., Beraldo P., Boeckh A., Cobb R.: Anthelmintic resistance in cyathostomin populations from horse yards in Italy, United Kingdom and Germany. Parasit. Vectors 2009, 2 (suppl 2) S2 doi: 10.1186/1756-3305-2-S2-S2

34. Trawford A. F., Burden F., Hodgkinson J. E.: Suspected moxidectin resistance in cyathostomes in two donkey herds at the Donkey Sanctuary, UK, [in:] Proc. of the $20^{\text {th }}$ International Conference of the World Association for the Advancement of Veterinary Parasitology, Christchurch, New Zealand 2005, 16-20 October, p. 196.

35. Waller P. J.: Anthelmintic resistance and the future for roundworm control. Vet. Parasitol. 1987, 25, 177-191.

36. Wolstenholme A. J., Fairwether I., Prichard R., von Samson-Himmelstjerna G., Sangster N. C.: Drug resistance in veterinary helminths. Trends Parasitol. 2004, 20, 469-476.

Corresponding author: Małgorzata Raś-Noryńska, DVM, PhD, ul. Oczapowskiego 13, 10-719 Olsztyn, Poland; e-mail: malgorzata.ras@uwm.edu.pl 